\title{
ADAPTASI PEMBELAJARAN DI ERA NEW NORMAL MELALUI PEMANFAATAN E-MODUL BERBASIS MULTIMODAL BAGI PARA GURU MI AL-ISTIQLAL DESA CIBOLANGSARI KECAMATAN KLARI KARAWANG
}

\author{
Nurhattati Fuad, Desi Rahmawati dan Rugaiyah \\ Manajemen Pendidikan, Universitas Negeri Jakarta) \\ Jl. Rawamangun Muka, Kota Jakarta Timur, Daerah Khusus Ibukota Jakarta, 13220. \\ E-mail: Desi-Rahmawati@unj.ac.id
}

\begin{abstract}
ABSTRAK. Bagi sebagian guru pembelajaran daring menjadi tantangan tersendiri karena guru dituntut untuk mampu menggunakan multimedia dalam pembelajaran akan tetapi belum semua guru cepat beradaptasi dengan penggunaan teknologi informasi, akibatnya pembelajaran daring menjadi terhambat. Padahal kemampuan teknologi informasi menjadi keharusan bagi guru profesional. Permasalahan yang dihadapi oleh mitra saat ini adalah para guru masih terkendala dalam merancang pembelajaran berbasis teknologi informasi dengan kondisi sebagai berikut:(1) guru belum memiliki keterampilan dalam pemanfaatan IT (2) guru belum terbiasa melakukan pembelajaran daring. Untuk mengatasi permasalahan tersebut makamemberikan pelatihan kepada guru melalui pelatihan penyusunan e-modul berbasis multimodal. Metode yang digunakan yaitu pemaparan materi, demonstrasitanya jawab. Setelah dilakukan pelatihan mengetahui situs untuk membuat modul berbasis multimodal yaitu dengan menggunakan situs www.bookcreator.com. Selanjutnya para peserta juga mengetahui kegunaan dari fitur-fitur yang disediakan di dalam situs tersebut, diantaranya fitur untuk menambahkan audio, menambahkan gambar dan video sehingga tidak sekedar teks saja. Selain itu dalam menyusun emodul berbasis multimodal ini juga para peserta dapat mengaitkan link pembelajaran yang sudah dibuat sebelumnya ke dalam website. Sehingga dapat disimpulkan bahwa kegiatan pelatihan yang dilakukan melalui pemberian video tutorial dan dilanjutkan dengan pelatihan secara daring dapat menambah wawasan dan pemahaman peserta dalam memanfaatkan media digital dalam membuat emodul pembelajaran sehingga isi pembelajaran tidak hanya dalam bentuk teks, tetapi juga dapat divariasikan dengan suara, gambar bahkan video.
\end{abstract}

Kata kunci: e-modul; multimodal; pelatihan

ABSTRACT. For some teachers, teaching online was a very challenges because teachers have been able to use multimedia in learning. But not all teachers can adapt to the use of technology, as a result learning becomes hampered. In this age the ability of information technology is a must for professional teachers. The problem faced that teachers were still constrained in designing information technology-based learning with the following conditions: (1) teachers did not have skills in using IT (2) teachers were not used to doing online learning. To overcome these problems, this workshop activity aims to provide training to teachers through the designing of multimodal-based e-modules. The method used is material presentation, demo, and question and answer. After it was done, the participants knew the site to create a multimodal-based module, namely by using the website www.bookcreator.com. Furthermore, the participants also learned about the usefulness of the features provided on the site, including features for adding audio, adding images and videos so that it is not just text. In addition, in compiling this multimodal-based e-module, participants can also link the previously created learning links to the website. So it can be said that training activities carried out through the provision of video tutorials and online training can add new insight and understanding of participants in utilizing digital media in making learning modules so that mode of learning is not only in text form, but can also be varied with sound, images, and videos.

Keywords: e-module; hypercontent; workshop

\section{PENDAHULUAN}

Hampirseluruhnegara di duniasangatmerasakan dampak yang ditimbulkan dari covid-19 ini. Seluruh sektor kehidupan terkena dampak dari wabah, tak terkecuali sektor pendidikan. Dengan adanya pandemi ini, Menteri Pendidikan dan Kebudayaan Republik Indonesia akhirnya mengeluarkan Surat Edaran Nomor 4 Tahun 2020 yang menyatakan bahwa proses belajar mengajar harus dilakukan dari rumah masing-masing. Menurut Rahmawati,dkk bahwa dampak yang ditimbulkan dari pandemi covid-19 pada proses pembelajaran seperti, peserta didik yang sulit memahami materi yang disampaikan dan rasa malas pada peserta didik sehingga ada campur tangan orangtua, kakak ataupun asisten rumah tangga pada setiap pekerjaan tugas rumah, termasuk ulangan (Rahmawati, 2020: 141). Selain itu dampak lainnya menurut Putri,dkk mengatakan bahkan ada peserta didik yang tidak mengikuti pembelajaran sama sekali dari awal hingga akhir sehingga menyebabkan guru merasa bingung dan kesulitan dalam proses penilaian pada peserta didik. Selain itu lamanya kegiatan pembelajaran dari rumah mengakibatkan peserta didik merasa sangat bosan dan jenuh belajar. Tentunya ada keinginan anak untuk segera sekolah agar dapat bertemu dan bermain dengan teman-temannya. Selain itu masih banyak orangtua yang bekerja sehingga tidak dapat membimbing peserta didik dalam pembelajaran (Putria,dkk, 2020: 869). 
Oleh karena itu, salah satu cara agar kegiatan pembelajaran terus berjalan, pemerintah menerapkan kebijakan untuk melaksanakan kegiatan pembelajaran jarak jauh, salah satu sistem yang bisa digunakan pada saat ini adalah memanfaatkan blended learning. Blended learning dikutip oleh Dwiyanto merupakan perpaduan antara pembelajaran tatap muka dan pembelajaran online yang dapat meningkatkan efektifitas, akses dan akseptabilitas dalam pengembangan potensi individu siswa (Dwiyanto, 2020: 4). Hal ini dilakukan setidaknya karena tiga alasan, yaitu: pengembangan pedagogik, peningkatan akses dan fleksibilitas, serta efektivitas biaya. Dengan adanya penyesuaian kurikulum dan pembelajaran di masa pandemi, maka sekolah dan guru harus siap menyesuaikan diri. Sekolah harus siap dengan perencanaan kurikulum. Guru juga harus mampu meningkatkan kompetensi dalam merancang pembelajaran dan menguasai berbagai model pembelajaran yang inovatif berbasis teknologi informasi. Akan tetapi, kondisi di lapangan, para guru masih perlu dibekaliketerampilan dalam merencanakan pembelajaran agar kualitas pembelajaran tetap tercapai.

Salah satu yang menjadi sasaran kegiatan pengabdian pada masyarakat adalah para guru di MI Al-Istiqlal. Berdasarkan hasil observasi dan wawancara, terlihat bahwa para guru MI Al-Istiqlal masih mengalami kendala dalam membuat modul berbasis multimodal. Sejauh ini bahan ajar masih dalam bentuk teks, belum divariasikan dengan suara ataupun video. Jika pun ada, belum terintegrasi dalam satu modul. Permasalahan tersebut disebabkan oleh berbagai faktor, diantaranya adalah:

1. Kurangnya pengetahuan guru tentang cara menyusun e-modul berbasis multimodal.

2. Terbatasnya kemampuan guru dalam mencari referensi untuk penyusunan e-modul berbasis multimodal.

Permasalahan tersebut dipandang perlu untuk diberikan solusi sehingga kegiatan pembinaan dan pengembangan guru untuk meningkatkan profesionalisme dapat dilaksanakan secara optimal. Untuk itu diperlukan sebuah terobosan baru untuk memecahkan permasalahan tersebut melalui program pelatihan e-modul berbasis multimodal. Hal ini mengingat dalam kondisi pandemi siswa butuh pemahaman yang lebih dari sekedar teks, tetapi juga melalui audio dan video. Sebagaimana hasil penelitian yang dilakukan oleh Prawiradilaga et al (2017) bahwa penggunaan e-modul berbasis multimodal memberikan kesempatan bagi penggunanya untuk mempelajari dari sisi mana saja sesuai kebutuhan belajar. Riset lainnya dilakukan oleh Hidayat et al (2020) menyatakan bahwa modul berbasis hypercontent dapat menjadi media belajar mandiri bagi siswa. Isi materi kompleks dilengkapi dengan fitur-fitur gambar bergerak, video, serta artikel menarik lainnya yang telah disediakan dan dapat diakses secara online melui scan barcode dengan memanfaatkan aplikasi QR Code Reader pada smartphone android.

Berdasarkan hasil riset yang telah dilakukan terkait manfaat menggunaan emodul berbasis multimodal, maka kegiatan pelatihan penyusunan e-modul berbasis multimodal bagi para guru MI penting untuk dilakukan. Pelatihan difokuskan pada peningkatan kemauan dan kemampuan guru menulis bahan ajar berupa e-modul berbasis multimodal. Harapannya guru-guru menjadi produktif dalam menghasilkan e-modul.

\section{METODE}

Metode yang digunakan dalam kegiatan ini adalah: pemaparan materi, demonstrasitanya jawab. metode demonstrasi yaitu dengan melakukan curah pendapat antarguru dan menjelaskan langkahlangkah. Upaya tersebut berdampak pada peningkatan profesionalisme guru.

Tahapan dalam kegiatan pelatihan ini adalah sebagai berikut.

1. Menyusun materi sosialisasi dan pelatihan

2. Menyusun rencana program pendampingan

3. Berkoordinasi dengan pihak Yayasan Ma'had AlIstiqlal Karawang serta dinas pendidikan setempat

4. Menghimpun data guru yang akan terlibat dalam kegiatan pengabdian kepada masyarakat

5. Melaksanakan kegiatan pelatihan penyusunan e-modul berbasis multimodal

6. Melakukan evaluasi terhadap rangkaian kegiatan dalam program pengabdian kepada masyarakat

7. Menyusun laporan program pengabdian kepada masyarakat.

\section{HASIL DAN PEMBAHASAN}

Kegiatan pengabdian masyarakat ini dilaksanakan mulai dari persiapan, pelaksanaan sampai pelaporan. Sebelum pelatihan di mulai, para pemateri melakukan rekaman terlebih dahulu dan mengupload rekaman ke dalam youtube agar para peserta mendapatkan bekal awal sebelum memasuki pelatihan, Adapun link youtube yang digunakan peserta untuk memahami penggunaan book creator sebagai berikut: https://youtu.be/j8A1Woek_PQ. Selanjutnya dilaksanakan pelatihan secara daring melalui via zoom cloud meeting.

Pada sesi pemaparan materi pemanfaatan e-modul berbasis multimodal narasumber mengawali dengan penyampaian konsep literasi digital sebagai 
pijakan awal terkait peluang apa yang dapat dilakukan dengan adanya kemudahan teknologi saat ini.

Pemaparan materi disampaikan dengan rinci oleh narasumber dan peserta pelatihan menyimak materi yang disampaikan dengan antusias karena diselingi oleh ice breaking, sehingga peserta pelatihan tidak bosan dalam mengikuti kegiatan pelatihan ini.

Selanjutnya, yaitu sesi mendemonstrasikan pembuatan e-modul berbasis multimodal dengan menggunakan bookcreator yang dipraktekkan oleh pemandu. Adapun tahapan-tahapan dalam membuat e-modul sebagai berikut:

1. Mendaftar di website www.bookcreator.com. Untuk registrasi dapat menggunakan akun gmail untuk mempermudah dalam penggunaan bookcreator.

2. Membuat akun bookcreator. Selanjutnya memilih tingkatan kelas dan mata pelajaran yang sesuai.

3. Membuat perpustakaan kelas. Bookcreator memfasilitasi pengguna dalam satu perpustakaan untuk membuat sebanyak 40 buku.

4. Membuat modul. Untuk mengawali membuat modul dapat mengklik new book

5. Memilih template modul. Pilihan template modul dapat berupa bentuk blank atau template yang sudah disediakan oleh bookcreator.

6. Menambahkan isi materi dalam modulAgar modul terlihat menarik, anda perlu mengisi materi dalam modul. Terbagi menjadi tombol "+", tombol "i" dan tombol ">"

Bookcreator ini dapat menyimpan modul secara bersama di satu tempat, yaitu dengan cara membagikan kode invite to library.

Setelah didemonstrasikan tahapan-tahapan dalam membuat e-modul selanjutnya dilakukan sesi tanya jawab. Para peserta antusias dalam menanyakan pertanyaan mengenai cara penyusunan bahan ajar berupa e-modul berbasis multimodal menggunakan bookcreator. Kegiatan pelatihan yang terdiri dari tiga sesi ini berjalan dengan baik.

Melalui pelatihan tersebut, para peserta diperkenalkan dan dijelaskan mengenai penyusunan e-modul berbasis multimodal menggunakan bookcreator, para peserta dilatih untuk terbiasa menggunakan bookcreator dalam menyusun e-modul berbasis multimodal. Secara keseluruhan para peserta sudah memiliki bekal pemahaman yang baik terhadap pemanfaatan bookcreator dalam menyusun e-modul berbasis multimodal.

Pelatihan ini untuk menjawab tantangan pembelajaran abad-21 yang mensyaratkan pendidik untuk memiliki kecakapan digital (literasi digital) yang baik sehingga dapat mengoptimalkan perkembangan teknologi informasi yang semakin pesat sebagaimana dikemukakan oleh Chalkiadakis
(2018:10) bahwa setidaknya terdapat 6 indikator dari literasi digital, yaitu :

1) Confidence in the use of media and ICT, 2) Proficiency in the use of digital tools, 3) Interactive digital skills, 4) Critical use of digital tools (analysis, critique, evaluation, creation), 5) Ability to attend to ethical responsibilities required in complex environments, 6) Participatory culture in technology.

Dari indikator-indikator literasi digital yang telah disebutkan di atas, tampak bahwa literasi digital bukan hanya sebatas kecakapan dalam menggunakan perangkat digital semata, tetapi juga memperhatikan aspek etika dan budaya dalam bermedia digital dan Media digital dalam pembelajaran daring salah satunya pemanfaatan bookcreator. Menurut Othman, Model VARK menunjukkan bahwa ada empat tipe utama pembelajar: visual, auditori, membaca/ menulis, dan kinestik. Dengan pemanfaatan bookcreator memungkinkan siswa lebih antusias dalam belajar karena modul lebih interaktif.

\section{UCAPAN TERIMAKASIH}

Pihak yang terkait dalam kegiatan ini adalah; (1) Kepala Satuan Pendidikan sebagai mitra yang memberikan kewenangan dan perizinan kegiatan; (2) Pembina Yayasan sebagai bentuk binaan terhadap guru-guru di wilayah yang menjadi binaannya; dan (3) Bagi guru yang bersangkutan dapat mendukung peningkatan kemampuannya dalam penyusunan e-modul berbasis multimodal.

\section{DAFTAR PUSTAKA}

Chalkiadakis, A. 2018. A Systematic Literature Review of $21^{\text {st }}$ Century Skills and Competencies in Primary Education. International Journal of Instruction, 11(3), 10-16. http://doi.org/10.12973/iji.2018.1131a

Dwiyanto, H. 2020. Menyiapkan Pembelajaran dalam Memasuki "New Normal" dengan Blended Learning. http://lpmplampung. kemdikbud.go.id/po-content/uploads/New Normal_Blended_Learning_artikel_sec.pdf

Hidayat Moh. Rizqi dan Rusijono. Pengembangan Modul Berbasis Hypercontent Materi Prinsip Dasar Pembuatan Animasi 2D Mata Pelajaran Animasi $2 D$ dan $3 D$ kelas XI Muldimedia di SMK Muhammadiyah 2 Taman. Universitas Negeri Surabaya.

Prastowo, A. 2014. Panduan Kreatif membuat Bahan Ajar Inovatif, (Yogyakarta: Diva Press) 
Prawiradilaga, Dewi etal. 2017. Prinsip-Prinsip Dasar Pengembangan Modul Berpendekatan Hypercontent. Indonesian Journal of Curriculum and Educational Technology Studies. http://journal.unnes.ac.id/sju/index. php/jktp

Putria, H dkk. 2020. Analisis Proses Pembelajaran Dalam Jaringan (Daring) Masa Pandemi
Covid-19 pada Guru Sekolah Dasar. Jurnal Basicedu, 4(4), 869-870. https://doi. org/10.31004/basicedu.v4i4.460

Rahmawati, NR, dkk, 2020. Analisis Pembelajaran Daring saat Pandemi di Madrasah Ibtidaiyah. Journal of Primary Education. 1(2). 139-148. https://doi.org/10.30762/sittah.vli2.2487 